\begin{tabular}{|l|l|l|l|l|l|} 
J. Tek. Ling & Vol.11 & No.3 & Hal. 493 - 502 & Jakarta, September 2010 & ISSN 1441-318X \\
\hline
\end{tabular}

\title{
DINAMIKA DAN STATUS MUTU AIR WADUK SEI NONGSA
}

\author{
Yudhi Soetrisno Garno \\ Peneliti Dinamika Kualitas Perairan \\ Badan Pengkajian dan Penerapan Teknologi
}

\begin{abstract}
Sei Nongsa is a reservoir in the Batam Industrial Development Area (BIDA), which developed especially for source of drinking water. This research was conducted to know the water quality status of Sei Nongsa, and the suitability for the source of drinking water. This research revealed that the water of Sei Nongsa can not directly used for drinking water due to concentrations of detergent, $\mathrm{Cu}, \mathrm{Cr}, \mathrm{Cd}$ and $\mathrm{Pb}$ were higher than the national standard for drinking water. Base on this result, it was suggested that the water of Sei Nongsa need threatment for decrease the above parameters
\end{abstract}

Key words: Nongsa, water quality status.

\section{PENDAHULUAN}

\subsection{Latar Belakang}

Pulau Batam merupakan salah satu daerah terluar Indonesia yang ditetapkan sebagai "Bounded Ware-house Area", dengan berbagai macam kegiatan industri. Penetapan "Bounded Warehouse Area" tersebut menjadikan daerah ini berkembang dengan pesat disegala bidang industri, dan infrastrukturnya, termasuk peningkatan kebutuhan air bersih. Lemtek Universitas Indonesia (UI) memprediksikan bahwa pada tahun 1996, Batam membutuhkan air bersih sebanyak 1.490,73 I/detik, dan pada tahun 2006 menjadi 3.916,76 I/detik ${ }^{1)}$.

Kebutuhan air bersih yang besar tersebut, secara alamiah tidak mungkin dapat dipenuhi oleh sumberdaya air yang ada di P. Batam karena secara alamiah kondisi/tekstur tanah pulau Batam sulit untuk meresapkan air, sehingga air hujan yang jatuh ke permukaan tanah lebih banyak yang mengalir dipermukaan dan terbuang ke laut ${ }^{2}$.
Sementara itu air yang ada dalam tanah, berdasarkan analisa geo listrik di beberapa tempat di P. Batam didapatkan sudah payau dan sebagian telah terkontaminasi oleh air rawa.

Sifat tanah yang tidak mampu meresapkan dan menyimpan air hujan serta air tanah yang berkualitas kurang baik tersebut, menghantarkan Otoritas Pengelolaan Daerah Industri Pulau (OPDIP) membangun beberapa waduk, termasuk Sei Nongsa guna menampung air hujan, yang secara alami di Batam memiliki intensitas dan kuantitas yang cukup tinggi. Selain Nongsa yang terletak di wilayah utara P. Batam, telah dibangun dan dioperasikan pulau 6 buah waduk buatan, yakni Waduk Sei (W.S.) Mukakuning, W.S. Ladi, W.S. Nongsa, W.S. Mukakuning dan W.S. Duriangkang. Secara keseluruhan waduk-waduk tersebut tersaji pada Tabel-1 ${ }^{3)}$. 
Tabel-1. Sumber dan Instalasi Air Bersih di P. Batam.

\begin{tabular}{|l|l|l|}
\hline Sumber air W.S.- & Kapasitas sumber & Kapasitas instalasi \\
\hline Baloi & 30,00 & 30,00 \\
\hline Ladi & 240,00 & 240,00 \\
\hline Harapan & 210,00 & 210,00 \\
\hline Nongsa & 60,00 & 60,00 \\
\hline Muka Kuning & 310,00 & 310,00 \\
\hline Duriangkang & $3.000,00$ & $3.000,00$ \\
\hline
\end{tabular}

Sumber: Lemtek UI 1).

\subsection{Air Bersih}

Peraturan Pemerintah Republik Indonesia No 82 tahun 20014). tentang Pengelolaan kualitas air dan pencemaran air, menggolongkan air dari suatu sumber air kedalam 4 kelas:

i. Kelas satu, air yang peruntukannya dapat digunakan untuk air baku air minum, dan atau peruntukan lain yang mempersyaratkan mutu air yang sama dengan kegunaan tersebut;

ii. Kelas dua, air yang peruntukannya dapat digunakan untuk prasarana/ sarana rekreasi air, pembudidayaan ikan air tawar, peternakan ,air untuk mengairi pertanaman, dan atau peruntukkan lain yang mempersyaratkan mutu air yang sama dengan kegunaan tersebut;

iii. Kelas tiga, air yang peruntukannya dapat digunakan untuk pembudidayaan ikan air tawar, peternakan, air untuk imengairi pertanaman, dan atau peruntukan lain yang mempersyaratkan air yang sama dengan kegunaan tersebut;

iv. Kelas empat, air yang peruntukannya dapat digunakan untuk mengairi,pertanaman dan atau peruntukan lain yang mempersyaratkan mutu air yang sama dengan kegunaan tersebut.

Setiap kelas air tersebut mempunyai karakteristik sendiri-sendiri, namun demikian karena kelas 1 dan 2 berhubungan langsung dengan kebutuhan primer manusia maka
Kelas 1 dan 2 lebih ketat daripada Kelas lainnya, khususnya pada parameterparameter logam berat

W.S. Nongsa dibangun dalam rangka peningkatan ketersediaan air bersih guna memenuhi kebutuhan air baku di Batam yang terus meningkat. Berkenaan dengan hal tersebut, maka kualitas air W.S. Nongsa harus selalu memenuhi kriteria untuk bahan baku air bersih. Oleh karena itu maka perubahan (dinamika) nilai parameter kualitas air harus selalu dimonitor dan status mutu air harus diketahui sehingga jika terjadi perubahaan kualitas yang berdampak negatif, misalnya karena pencemaran dapat segera diatasi. Yang dimaksud mutu air pada artikel ini adalah sesuai dengan batasan pada pasal-1 ayat b Keputusan Menteri Negara Lingkungan Hidup Nomor 115 Tahun 2003 tentang Pedoman Penentuan Status Mutu Air ${ }^{6}$. Kepmen No. 115 Th. 2003 tersebut menetapkan bahwa status mutu air adalah tingkat kondisi mutu air yang menunjukkan kondisi cemar atau kondisi baik pada suatu sumber air dalam waktu tertentu dengan membandingkan dengan baku mutu air yang ditetapkan.

Salah satu metode yang digunakan adalah metode storet dalam Kepmen No. 115 Th. $2003^{6}$. yang mengklasifikasikan mutu air dalam empat kelas, yaitu :

i. Kelas A : baik sekali, skor $=0$ tergolong memenuhi baku mutu

ii. Kelas B : baik, skor $=-1 \mathrm{~s} / \mathrm{d}-10$ tergolong cemar ringan

iii. Kelas C : sedang, skor $=-11 \mathrm{~s} / \mathrm{d}-30$ tergolong cemar sedang 
iv. Kelas $\mathrm{D}$ : buruk, skor $\geq-31$ tergolong cemar berat

\subsection{Tujuan}

Penelitian ini dilakukan dengan tujuan untuk mengetahui dinamika dan status mutu air perairan W.S. Nongsa di Batam

\subsection{Manfaat hasil Penelitian}

Hasil penelitian ini bermanfaat untuk:

i) Menjadi bahan pertimbangan bagi pengolah air dalam treatmen air baku menjadi air bersih.

ii) Mengetahui status mutu air W.S. Nongsa 1994.

iii) Data pembanding bagi evaluasi perubahan kualitas air W.S. Nongsa setelah 1994.

\section{METODOLOGI}

\subsection{Pengambilan sampel}

Penelitian ini dilakukan selama 4 bulan dari bulan Nopember 1993 sampai dengan Februari 1994. Pengambilan sampel dan pengukuran sifat fisik air dilakukan setiap 2 minggu sekali. Selama penelitian dilakukan 7 kali kegiatan lapangan yang terdiri dari pengamatan in-situ dan pengambilan sampel untuk analisis laboratorium. Pengamatan insitu meliputi pengukuran temperatur udara, air, kekeruhan, salinitas dan $\mathrm{pH}$. Temperatur udara diukur dengan termometer air raksa, sedangkan temperatur air, dan konduktivitas dengan SCT-meter.

Pengambilan sampel air untuk analisis laboratorium dilakukan dengan pipa PVC yang mempunyai panjang $3 \mathrm{~m}$ dan diameter 3 Cm. Pipa dimasukan (tegak lurus) . kedalam badan air sampai mencapai kedalaman 2 meter. Setelah itu bagian atas dan ujung pralon di tutup/sumbat dengan karet, pipa diangkat dengan pelahan-lahan ke atas dan ujung bawah pipa di masukan ke dalam ember. Dengan membuka tutup karet maka air akan menggelontor masuk kedalam ember.

Dari ember tersebut, air yang mewakili kedalaman $0 \mathrm{~m}$ (permukaan) sampai 2 meter diambil 2 liter sebagai sampel.. 1 liter dari padanya digunakan untuk analisis BOD, COD, fosfat, ammonium, nitrit, nitrat dan lainnya di laboratorium TPLH-OPDIP Batam, sedangkan 1 liter yang lain digunakan untuk analisis logam di laboratorium Biotrop-Bogor. Untuk lebih jelas maka metode pengukuran di lapangan dan analisis di laboratorium dapat di simak pada Garno (2003) ${ }^{7 \text {. }}$.

\subsection{Analisis Data}

Nilai setiap parameter kualitas air W.S. Nongsa hasil pengukuran di lapangan dan analisis sampel di laboratorium disajikan dalam bentuk tabel yang dilengkapi dengan nilai maksimum, minimun dan rata-ratanya. Selain itu tabel juga dilengkapi dengan nilai parameter yang sama dari air Kelas-1 lampiran Peraturan Pemerintah Republik Indonesia (PPRI) Nomor 82 Tahun 2001 tentang Pengelolaan kualitas air dan Pengendalian Pencemaran Air

Berdasarkan tabel tersebut kemudian dilakukan:

a. Analisis dinamika perubahan nilai setiap parameter

b. Penentuan status Mutu air dengan metode "Storet" sesuai Keputusan Menteri Negara Lingkungan Hidup Nomor 115 Tahun 20034).

\section{HASIL DAN PEMBAHASAN}

\subsection{Dinamika dan Kelayakan Air.}

Nilai masing-masing parameter kualitas air W.S. Nongsa dari 7 (tujuh) kali hasil pengukuran di lapangan dan analisis laboratorium disajikan pada tabel-2. Sesuai tujuan penelitian, yakni untuk mengetahui dinamika kualitas air dan kelayakannya sebagai sumber air baku maka pembahasan hasil penelitian tersebut (Tabel-2) difokuskan 
pada kesesuaian air W.S. Nongsa dengan ketentuan air kelas-1 pada Peraturan Pemerintah Republik Indonesia No 82 tahun 2001 tentang Pengelolaan kualitas air dan Pengendalian Pencemaran Air dan status mutu air dengan metode storet pada Keputusan Menteri Negara Lingkungan Hidup Nomor 115 Tahun 2003 tentang Pedoman Penentuan Status Mutu Air. Paper ini tidak banyak membahas hubungan nilai parameter pada tabel-2 dengan kesuburan perairan dan kesesuaian biota didalamnya.

\section{1) Parameter Fisika}

Selama penelitian temperatur air berfluktuasi antara $27,5-29^{\circ} \mathrm{C}$. Kisaran tersebut adalah kisaran yang wajar dan normal untuk temperatur air di daerah trofis. Selain memiliki kisaran temperatur yang normal, air W.S. Nongsa masih berbau normal dan memiliki warna yang masih alami yakni berkisar antara 0,15 - 3,5 PtCo. Meskipun PPRI No. 82 Tahun 2001 tidak membatasi nilai maksimum warna bagi peruntukan air Kelas satu, namun literatur yang ada mengungkapkan bahwa kisaran warna tersebut masih sangat layak untuk air baku air minum ${ }^{8}$.

Tabel-2 menunjukkan bahwa residu terlarut dalam air W.S. Nongsa masih rendah yakni hanya berkisar antara 4 - 32,6 mg/l. Residu terlarut adalah bahan-bahan terlarut (bahan berdiameter $<10^{-6} \mathrm{~mm}$ ) dan koloid (bahan berdiameter antara $<10^{-6}$ $--<10^{-3} \mathrm{~mm}$ ) yang berupa senyawa kimia dan bahan-bahan lain ${ }^{9}$. Nilai residu terlarut perairan dipengaruhi oleh pelapukan batuan, limpasan dari tanah dan kegiatan manusia disekitar badan air. Dengan demikian maka rendahnya residu terlarut mengisaratkan bahwa air W.S. Nongsa belum banyak menampung buangan yang mengandung senyawa anorganik yang larut. Nilai residu terlarut tersebut masih jauh dibawah nilai maksimum untuk air kelas-1 yakni 1000 mg/l, yang berarti bahwa air W.S. Nongsa tidak bermasalah untuk dijadikan air baku air minum. Seperti residu terlarut, air W.S. Nongsa juga mengandung residu tersuspensi yang rendah yakni hanya berkisar antara 1,2 - 41,4 mg/l. Nilai tersebut lebih rendah dari ketentuan nilai residu tersuspensi untuk air Kelas satu pada PPRI No.82 Tahun 2001 yang $50 \mathrm{mg} / \mathrm{l}$. Artinya perairan W.S. Nongsa tidak masalah (layak) dijadikan air baku air minum.

\section{2) Kimia Anorganik}

\section{A. Non-Logam}

Selama penelitian $\mathrm{pH}$ air W.S. Nongsa berkisar antara 5,5-6,8. Nilai pH 5,5 terukur dua kali yakni pada minggu ke-3 bulan Desember dan minggu pertama bulan Februari, sedangkan pada saat sampling yang lain nilai selalu $\mathrm{pH}>6,0$. Mengingat PPRI No. 82 tahun 2001 menetapkan bahwa air Kelas satu yakni air untuk air baku air minum harus memiliki pH antara 6-9 maka disimpulkan bahwa air W.S. Nongsa tidak setiap saat dapat dijadikan air baku air minum. Sebelum dijadikan air minum, air waduk harus dinaikan nilai $\mathrm{pH}$ nya menjadi $>6$.

Biological oxygen demand yang disingkat BOD adalah jumlah oksigen yang dibutuhkan oleh mikroba aerob untuk mengoksidasi bahan organik menjadi karbon dioksida dan air. Selama penelitian air W.S. Nongsa memiliki nilai BOD berkisar antara $0,24-2,16 \mathrm{mgO}_{2} / l$. Literatur yang ada mengemukakan bahwa nilai BOD-5 perairan alami adalah berkisar 0,5-7,0 mg/

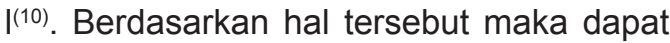
disimpulkan bahwa air W.S. Nongsa masih belum tercemar bahan organik. Meskipun demikian, namun karena PPRI No.82 Tahun 2001 telah menetapkan nilai BOD tertinggi untuk air baku air minum adalah $2 \mathrm{mg} \mathrm{O}_{2} / \mathrm{l}$ maka berdasarkan nilai BODnya, air W.S. Nongsa tidak layak untuk dijadikan air baku air minum.

Keberadaan pencemar organik dalam badan air juga dapat diukur dengan 
parameter chemical oksigen demand (COD). COD didefinisikan sebagai jumlah total oksigen yang diperlukan untuk mengoksidasi bahan organik secara kimiawi, baik yang dapat didegradasi secara biologis maupun yang sukar didegradasi secara biologis. Nilai COD, W.S. Nongsa selama penelitian berkisar antara 4,37-19,84 $\mathrm{mgO}_{2} / \mathrm{l}$. Pada umumnya nilai COD perairan alami adalah lebih kecil dari $20 \mathrm{mgO}_{2} /$ l. Sehingga dengan demikian maka berdasarkan nilai COD yang terukur maka air W.S. Nongsa belum tercemar oleh organik.

Bahan (pencemar) organik dalam badan air yang aerob selalu membutuh kan oksigen untuk mengoksidasinya. Oleh sebab itu maka keberadaan bahan organik dalam badan air selalu menyebabkan oksigen terlarut dalam badan air menjadi rendah, kecuali ada supplai oksigen secara kontinyu. Konsentrasi oksigen terlarut dalam air W.S. Nongsa berkisar antara 5,8-6,8 $\mathrm{mgO}_{2} / \mathrm{l}$. Publikasi yang ada mengungkapkan bahwa secara teoritis pada kisaran temperatur air antara $27,5-29,0{ }^{\circ} \mathrm{C}$, oksigen terlarut mencapai jenuh pada kisaran 7,69-7,97 $\mathrm{mg} / \mathrm{I}^{(11)}$. Ini mengisyaratkan bahwa oksigen terlarut pada air W.S. Nongsa tidak dapat mencapai kondisi jenuhnya. Mengingat sampling dilakukan di siang hari, saat fotosintesa telah menghasilkan oksigen maka fenomena seperti ini mengindikasikan bahwa supplai oksigen dari hasil fotosintesa dan difusi udara tidak lebih besar dari penggunaan oksigen terlarut oleh organisme untuk respirasi dan bakteri aerob untuk kegiatan dekomposisi organik yang ada dalam badan air.

PPRI No. 82 tahun 2001 menetapkan bahwa air untuk air baku air minum harus memiliki oksigen terlarut $>6 \mathrm{mg} / \mathrm{l}$. Dengan demikian maka meskipun nilai $<6 \mathrm{mg} / \mathrm{l}$ hanya terukur pada saat sampling terakhir yakni pada bulan Februari minggu ketiga namun tetap harus disimpulkan bahwa air W.S. Nongsa tidak selalu memenuhi persyaratan air baku air minum.

Dalam penelitian ini fosfat yang diukur ádalah orthofosfat. Orthofosfat sampai di badan air terutama berasal dari limbah detergen dan limpasan daerah pertanian. Fosfat sampai pada konsentrasi tertentu baik untuk kesuburan air, namun jika berlebihan berdampak negatif karena mengakibat-kan yutrofikasi dan merangsang pertumbuhan ganggang secara tak terkendali. Literatur yang ada mengemukakan bahwa dengan fosfat terlarut $>0.010 \mathrm{mgP} / \mathrm{l}$, ganggang air (fitoplankton) tumbuh dengan pesat ${ }^{12}$.

Konsentrasi fosfor pada perairan alami berkisar antara 0,005-0,02 $\mathrm{mg} \mathrm{PO}_{4}-\mathrm{P} / \mathrm{lt}^{8}$. . Di W.S. Nongsa konsentrasi orthofosfat berkisar antara 0,02-3,375 mg/l. Dengan kisaran tersebut maka air W.S. Nongsa sudah tergolong perairan yang subur; yang diduga karena tercemar oleh fosfor dari detergen yang berasal dari kegiatan masyarakat sekitar waduk. Mengacu PPRI No. 82 tahun 2001 yang menetapkan air untuk air baku air minum harus mengandung total fosfat < $0,2 \mathrm{mgP} / \mathrm{l}$ maka perairan W.S. Nongsa tidak layak dijadikan air baku air minum.

Penelitian ini mengukur nitrogen anorganik dalam bentuk amonium-N. nitrit-N, dan nitrat-N. Perairan alami pada umumnya mengandung amonia dengan konsentrasi < $0,1 \mathrm{mg} / \mathrm{l}$; nitrit dengan konsentrasi sekitar $0,001 \mathrm{mg} / \mathrm{l}$; nitrat dengan konsentrasi sekitar 0,1 mg/l. Tabel-2 menunjukkan bahwa amonium-N dalam air W.S. Nongsa berfluktuasi pada kisaran antara 0,006-0,087 $\mathrm{mgN} / \mathrm{l}$; nitrit-N berkisar antara 0,001-0,003 $\mathrm{mgN} / \mathrm{l}$ dan nitrat-N berkisar antara 0,001$0,484 \mathrm{mgN} / \mathrm{l}$.

Dibandingkan dengan nilai nitrogen pada PPRI No. 82 tahun 2001, ketiga bentuk nitrogen tersebut masih berada dibawah konsentrasi maksimum yang ditentukan untuk air kelas-1. Ini berarti bahwa air W.S. Nongsa layak dijadikan air baku air minum. Fenomena tersebut juga mengisaratkan bahwa pencemaran organik di perairan W.S. Nongsa memang masih tergolong rendah, sehingga hasil degradasi dalam bentuk senyawa-senyawa nitrogenpun masih rendah. 
Sulfur merupakan salah satu elelem esensial bagi makluk hidup. Di perairan, sulfur ditemukan dalam beberapa bentuk yaitu sulfida $\left(\mathrm{S}^{2-}\right)$, hidrogin sulfida $\left(\mathrm{H}_{2} \mathrm{~S}\right)$, besi sulfida (FeS, sulfur oksida $\left(\mathrm{SO}_{2}\right.$, sulfit $\left(\mathrm{SO}_{3}\right)$ dan sulfat $\left(\mathrm{SO}_{4}\right)$. Diantara bentuk-bentuk sulfur tersebut sulfat merupakan bentuk sulfur utama dalam badan air ${ }^{8)}$. Konsentrasi sulfat pada perairan alami berkisar antara 2-80 mg/l, sedangkan $\mathrm{H}_{2} \mathrm{~S}$ pada umumnya kecil sekali bahkan mendekati nol, kecuali pada lapisan air tanpa oksigen terlarut. Literatur yang ada mengungkapkan bahwa WHO memberi rekomendasi agar kandungan sulfat untuk air baku air minum sekitar 0,004 $\mathrm{mg} / \mathrm{l}$ dan $\mathrm{H}_{2} \mathrm{~S}$ sekitar $0,05 \mathrm{mg} / \mathrm{I}^{13)}$.

Kandungan sulfat dalam air W.S. Nongsa berkisar antara 0,001-1,18 mg/l sedangkan sulfida stabil pada konsentrasi $0,001 \mathrm{mgS} / \mathrm{l}$. Konsentrasi kedua bentuk sulfur tersebut jauh dibawah ketentuan PP No. 82 tahun 2001 yang menetapkan konsentrasi sulfat $400 \mathrm{mg} / \mathrm{l}$ dan sulfida $0,002 \mathrm{mg} / \mathrm{l}$. Dengan demikian maka air W.S. Nongsa berdasarkan kandungan sulfur didalamnya masih layak menjadi air baku air minum.

\section{2) Logam}

Pada penelitian ini parameter logam yang diukur adalah Magnesium (Mg), Kalsium (Ca), Besi (Fe), Seng (Zn), Mangan (Mn),

Magnesium (Mg) dan kalsium (Ca) adalah elemen penentu kesadahan air. Makin tinggi konsentrasi kedua elemen tersebut air makin sadah, yang dapat mempercepat korosi pada alat-alat yang terbuat dari besi dan mengakibat-kan sabun kurang berbusa. Literatur yang ada mengungkapkan bahwa di perairan alami kandungan magnesium berkisar antara 1-100 mg/l, dan untuk keperluan air minum kandungan magnesium hanya diperbolehkan sampai $50 \mathrm{mg} / \mathrm{l}$. Sementara itu konsentrasi kalsium pada perairan alami biasanya kurang dari $15 \mathrm{mg} /$ dan untuk keperluan air minum $<75 \mathrm{mg} / \mathrm{l}^{8}$.
Selama penelitian magnesium berkisar antara 0,35-2,28 $\mathrm{mgMg} / \mathrm{lt}$; sedangkan kalsium berfluktuasi antara 0,001-0,685 mg $\mathrm{Ca} / \mathrm{l}$. Kisaran nilai kedua parameter tersebut jauh lebih kecil dari nilai masing-masing parameter tersebut pada PPRI No 82 tahun 2001, dimana untuk magnesium adalah sebesar $30 \mathrm{mg} \mathrm{Mg/l} \mathrm{dan} \mathrm{kalsium} \mathrm{sebesar}$ $75 \mathrm{mg} \mathrm{Ca/l.} \mathrm{Hal} \mathrm{ini} \mathrm{mengisaratkan} \mathrm{bahwa}$ berdasarkan kadar magnesium dan kalsium, air W.S. Nongsa layak menjadi air baku air minum. Selain magnesium dan kalsium konsentrasi seng ( $\mathrm{Zn}$ ) dan besi (Fe) di W.S. Nongsa sangat kecil. Di perairan alami konsentrasi seng pada umumnya $<5 \mathrm{mg} /$ ${ }^{15)}$. Meskipun bersifat toksik bagi organisme air, namun seng tidak bersifat toksik pada manusia; hanya pada konsentrasi tinggi seng akan merubah rasa air.

Selama penelitian, konsentrasi seng berfluktuasi pada kisaran 0,004-0,028 mg $\mathrm{Zn} / \mathrm{l}$, sedangkan besi ( $\mathrm{Fe}$ ) pada kisaran antara 0,001-0,283 mg Fe/l. Kisaran kedua logam tersebut jauh lebih kecil dari ketetapan air baku air minum dalam PPRI No.8 Tahun 2001 yang menetapkan konsentrasi seng 5 $\mathrm{mg} \mathrm{Zn} / \mathrm{l}$ dan besi $0,30 \mathrm{mg}$ Fe/l. Fenomena ini mengindikasikan bahwa berdasarkan kandungan seng dan besi, air W.S. Nongsa masih layak menjadi air baku air minum.

Selama penelitian, konsentrasi mangan (Mn) selalu 0,001 mg.Mn/l. Dibandingkan dengan ketentuan pada PPRI No.8 Tahun 2001 untuk air baku air minum yakni 0,1 $\mathrm{mg} \mathrm{Mn/l,} \mathrm{konsetrasi} \mathrm{tersebut} \mathrm{sangat} \mathrm{kecil.}$ Hal ini mengisaratkan bahwa berdasarkan kandungan mangan didalamnya; air W.S. Nongsa masih layak untuk air baku air minum.

\section{3) Logam Berat}

Logam berat adalah logam yang memiliki nomer atum besar. Logam ini biasanya berbahaya bagi kehidupan. Termasuk didalamnya adalah unsur-unsur kromium $(\mathrm{Cr})$, timbal $(\mathrm{Pb})$, tembaga $(\mathrm{Cu})$, and. kadmium (Cd), Di alam logam berat 
Tabel-2. Hasil pengukuran dan analisis parameter fisik dan kimia pada air contoh dari waduk Nongsa

\begin{tabular}{|c|c|c|c|c|c|c|c|c|c|c|c|c|c|}
\hline \multirow{3}{*}{ Parameter } & \multirow{3}{*}{ unit } & \multicolumn{7}{|c|}{ Hasil sampling pada bulan dan minggu ke- } & \multirow{2}{*}{\multicolumn{3}{|c|}{ Nilai }} & \multirow{3}{*}{$\begin{array}{c}\text { PP } \\
82 / 2001 \\
K-1\end{array}$} & \multirow{3}{*}{$\begin{array}{c}\text { Storet } \\
\text { S1 }\end{array}$} \\
\hline & & \multirow{2}{*}{$\begin{array}{c}\text { Nop. } \\
\text { III }\end{array}$} & \multicolumn{2}{|c|}{ Desember } & \multicolumn{2}{|c|}{ Januari } & \multicolumn{2}{|c|}{ Februari } & & & & & \\
\hline & & & 1 & III & 1 & III & I & III & Maks & Min & rata & & \\
\hline \multicolumn{14}{|l|}{ FISIKA } \\
\hline Temperatur & $0 \mathrm{C}$ & 28 & 27,5 & 28,5 & 27,5 & 29 & 28,5 & 27,5 & 29 & 27,5 & 28,07 & +3 & 0 \\
\hline Warna & Orgipto & - & 3,5 & 3,5 & 0,18 & 0,15 & 1,19 & 3,5 & 3,5 & 0,15 & 10,35 & & \\
\hline Bau-Rasa & PtCo & $\mathrm{nml}$ & $\mathrm{nml}$ & $\mathrm{nml}$ & $\mathrm{nml}$ & $\mathrm{nml}$ & $\mathrm{nml}$ & $\mathrm{nml}$ & $\mathrm{nml}$ & $\mathrm{nml}$ & $\mathrm{nml}$ & & \\
\hline $\mathrm{DHL}$ & $\begin{array}{l}\text { Umhs/ } \\
\mathrm{cm}\end{array}$ & 40 & 30 & 250 & 10 & 20 & 30 & 42 & 250 & 10 & 60,28 & & \\
\hline $\begin{array}{l}\text { Residu } \\
\text { Terlarut }\end{array}$ & $\mathrm{mg} / \mathrm{l}$ & - & 32,6 & 4 & - & - & - & - & 32,6 & 4 & 18,30 & 1000 & 0 \\
\hline $\begin{array}{l}\text { Residu } \\
\text { tersuspensi }\end{array}$ & $\mathrm{mg} / \mathrm{l}$ & 14,5 & 41,4 & 19,8 & 4 & 14,0 & 1,2 & 4,8 & 41,4 & 1,2 & 14,243 & 50 & 0 \\
\hline \multicolumn{14}{|c|}{ Kimia Anorganik } \\
\hline $\mathrm{pH}$ & & 6,6 & 6,8 & 5,5 & 6,6 & 6,1 & 5,5 & 6 & 6,8 & 5,5 & 6,2 & $6-9$ & 0 \\
\hline B.O.D-5 & $\mathrm{O} 2$ & 0,24 & 2,05 & 0,95 & 0,38 & 1,1 & 0,76 & 2,16 & 2,16 & 0,24 & 1,091 & 2 & -4 \\
\hline COD & $\mathrm{O} 2$ & 4,37 & 19,8 & 13,23 & 11,83 & 11,75 & 7,76 & 13,33 & 19,84 & 4,37 & 11,73 & 10 & -16 \\
\hline O2 Terlarut & $\mathrm{O} 2$ & 6,2 & 6,8 & 6,3 & 6,7 & 6,4 & 6,5 & 5,8 & 6,8 & 5,8 & 6,386 & 6 & -4 \\
\hline Ortho Posfat & $\mathrm{PO} 4$ & 0,095 & 0,334 & 0,02 & 3,375 & 0,815 & 0,170 & 1,074 & 3,375 & 0,02 & 0,840 & 0,2 & -16 \\
\hline Amoniak-N & $\mathrm{NH} 3$ & 0,04 & 0,049 & 0,04 & 0,006 & 0,032 & 0,087 & 0,018 & 0,087 & 0,006 & 0,039 & 0,50 & 0 \\
\hline Nitrat & $\mathrm{NO} 3$ & 0,001 & 0,001 & 0,001 & 0,001 & 0,484 & 0,145 & 0,113 & 0,484 & 0,001 & 0,107 & 10 & 0 \\
\hline Nitrit & NO2 & 0,003 & 0,001 & 0,001 & 0,003 & 0,001 & 0,002 & 0,001 & 0,003 & 0,001 & 0,002 & 0,06 & 0 \\
\hline Sulfat & $\mathrm{SO} 4$ & 1,18 & 0,72 & 0,001 & 0,001 & 0,044 & 0,132 & 0,593 & 1,18 & 0,001 & 0,382 & 400 & 0 \\
\hline Sulfida & H2S-S & 0,001 & 0,001 & 0,001 & 0,001 & 0,001 & 0,001 & 0,001 & 0,001 & 0,001 & 0,001 & 0,002 & 0 \\
\hline Magnesium & $\mathrm{Mg}$ & 1,0 & 0,85 & 0,38 & 0,35 & 0,46 & 0,63 & 2,28 & 2,28 & 0,35 & 0,850 & $(30)$ & 0 \\
\hline Calsium & $\mathrm{Ca}$ & 0,685 & 0,365 & 0,438 & 0,436 & 0,43 & 0,65 & 0,001 & 0,685 & 0,001 & 0,429 & $(75)$ & 0 \\
\hline Kadmium & $\mathrm{Cd}$ & 0,008 & 0,001 & 0,008 & 0,005 & 0,005 & 0,019 & 0,001 & 0,019 & 0,001 & 0,007 & 0,01 & -4 \\
\hline Kromium & $\mathrm{Cr}$ & 0,001 & 0,001 & 0,001 & 0,001 & 0,001 & 0,072 & 0,056 & 0,072 & 0,001 & 0,019 & 0,05 & -4 \\
\hline Tembaga & $\mathrm{Cu}$ & 0,001 & 0,001 & 0,001 & 0,001 & 0,001 & 0,027 & 0,001 & 0,027 & 0,001 & 0,005 & 0,02 & -4 \\
\hline Besi & $\mathrm{Fe}$ & 0,092 & - & 0,088 & 0,283 & 0,12 & 0,133 & 0,001 & 0,283 & 0,001 & 0,120 & 0,3 & 0 \\
\hline Timbal & $\mathrm{Pb}$ & 0,001 & 0,001 & 0,001 & 0,001 & 0,001 & 0,052 & 0,001 & 0,052 & 0,001 & 0,008 & 0,03 & -4 \\
\hline Mangan & $\mathrm{Mn}$ & 0,001 & 0,001 & 0,001 & 0,001 & 0,001 & 0,001 & 0,001 & 0,001 & 0,001 & 0,001 & 0,1 & 0 \\
\hline Seng & $Z n$ & 0,004 & 0,008 & 0,028 & 0,023 & 0,005 & 0,007 & 0,026 & 0,028 & 0,004 & 0,014 & 5 & 0 \\
\hline \multicolumn{14}{|c|}{ Kimia Organik } \\
\hline Detergen & MBAS & 0,25 & 0,453 & 0,61 & 0,034 & 0,286 & 0,048 & 0,045 & 0,61 & 0,034 & 0,247 & 0,200 & -16 \\
\hline $\mathrm{Jum} I$ ah & Skor & & & & & & & & & & & & -67 \\
\hline
\end{tabular}

Keterangan:

Angka I, II, III dan IV menunjukkan minggu pertama, kedua, ketiga dan keempat pada bulan tersebut.

PPRI 82/'2001 = Peraturan Pemerintah Republik Indonesia Nomor 82 Tahun 2001 tentang Pengelolaan kualitas air dan Pengendalian Pencemaran Air. K-1 adalah Air Kelas satu pada PPRI $82 / 2001$

Nilai $=$ Hasil analisis 7 kali sampling; Maks = nilai maksimal; Min = nilai minimal; rata $=$ rata-rata dari nilai

Storet $=$ metode penentuan mutu air sesuai Keputusan Menteri Negara Lingkungan Hidup Nomor 115 Tahun 2003 tentang Pedoman Penentuan Status Mutu Air.

S1 = Skor Storet untuk peruntukan air kelas-1 
ditemukan dalam jumlah yang kecil dan umumnya ditemukan dalam bentuk senyawa dengan sulfida atau kompleks mineral yang terdiri dari oksigen, silika dan sulfur. Selain itu logam berat ditemukan pula sebagai hasil sampingan dari kegiatan penambangan, seperti $\mathrm{Cd}$ yang ditemukan pada proses pencairan seng ${ }^{14)}$.

Kromium (Cr) adalah logam berwarna putih kebiru-biruan, yang sering digunakan terutama sebagai bahan campuran logam lain seperti stainless steel, bungkus pengaman pada logam dan maknit serta elektropleting. Di perairan alami sebenarnya kromium jarang ditemukan, dan jika ditemukan pada umumnya ada dalam bentuk $\mathrm{Cr}^{3+}$ dan $\mathrm{Cr}^{6+}$. Kromium dapat menyebabkan iritasi pada kulit, kerusakan hati, ginjal dan jaringan saraf. Perairan tawar pada umumnya mengandung kromium kurang dari 0,001 mg/l. Untuk menjadi air minum literatur yang ada menyarankan agar konsentrasi kromium dalam air lebih kecil 0,05 mg//(15). Saran tersebut sama dengan PPRI No.82 Tahun 2001 yang menetapkan kandungan $\mathrm{Cr}$ dalam air untuk air baku air minum maksimum $0,05 \mathrm{mg} \mathrm{Cr} / \mathrm{l}$.

Tabel-2 mengungkapkan bahwa selama penelitian konsentrasi kromium dalam Air W.S. Nongsa berkisar antara 0,001-0,072 $\mathrm{mg} \mathrm{Cr} / \mathrm{l}$. Kisaran tersebut menunjukkan bahwa air W.S. Nongsa tidak sesuai untuk air baku air minum; meskipun $\mathrm{Cr}>0,05 \mathrm{mg}$ hanya diperoleh 2 kali dari 7 kali analisa laboratorium. (Tabel-2)

Timbal (Pb) adalah logam yang berwarna putih kebiru-biruan, berat dan lunak tetapi inelastis. Kebanyakan timbal ditemukan dalam bentuk senyawa dengan unsur lain. Senyawa timbal diketahui memiliki daya racun yang kuat; dengan tingkat maksimum kontaminasi sekitar 0,015 $\mathrm{ml} / \mathrm{l}$. Timbal dipercaya menjadi penyebab hipertensi, ketidak normalan reproduksi, dan syaraf. Timbal banyak digunakan pada industri batere dan bahan tambahan pada gasoline. Di perairan ditemukan dalam bentuk terlarut dan tersuspensi; namun karena kelarutan timbal cukup rendah maka konsentrasi timbal dalam air relaif kecil. Perairan alami biasanya mengandung timbal dengan konsentrasi $<0,05 \mathrm{mg} / \mathrm{l}$. Semantara itu untuk air minum, air diperbolehkan mengandung timbal sampai $0,05 \mathrm{mg} / \mathrm{l}^{13,15}$.

Tabel-2 mengungkapkan bahwa selama penelitian konsentrasi timbal dalam Air W.S. Nongsa berkisar antara 0,001-0,052 mg Pb/l. meskipun nilai $\mathrm{Pb}>0,05 \mathrm{mg}$ hanya diperoleh 1 kali dari 7 kali analisa laboratorium (Tabel-2), namun kisaran tersebut menunjukkan bahwa air W.S. Nongsa tidak sesuai untuk air baku air minum.

Tembaga (Cu) adalah unsur essensial bagi organisme, dan merupakan logam yang biasa ditemukan dalam perairan. Pada perairan alami, konsentrasi tembaga biasanya $<0,02$ $\mathrm{mg} / \mathrm{l}$, dan untuk air minum diperbolehkan sampai $0,1 \mathrm{mg} / \mathrm{I}^{13)}$. Namun demikian PPRI No. 82 Tahun 2001 menetapkan Cu dalam air untuk air baku air minum maksimum 0,02mg/l. Kelebihan tembaga dapat mengakibatkan penyakit perut, usus, liver dan luka di ginjal, serta anemia.

Selama penelitian air W.S. Nongsa mengandung Tembaga (Cu) antara 0,001$0,027 \mathrm{mgCu} / \mathrm{l}$. Meskipun nilai $\mathrm{Cu}>0,02 \mathrm{mg}$ hanya diperoleh 1 kali dari 7 kali analisa laboratorium (Tabel-2), namun kisaran tersebut harus disimpulkan bahwa air W.S. Nongsa tidak sesuai untuk air baku air minum.

Kadmium (Cd) adalah unsur logam inorganik yang lunak berwarna putih kebirubiruan dan beracun. Keracunan kadmium ringan dapat mengakibatkan perut mual, muntah-muntah, diare, luka hati, shok dan gagal ginjal, sedangkan keracunan berat dapat mengakibatkan penyakit ginjal, liver, tulang rapuh dan kerusakan sel-sel darah. Kadmium tidak larut dalam air, dan oleh karenanya di badan air ditemukan dalam jumlah yang sangat sedikit ${ }^{8}$. Sumber alami kadmium adalah greenockite, hawleyite, sphalerite, dan otavite ${ }^{13)}$. Perairan tawar alami mengandung kadmium antara 0,0001 $0,01 \mathrm{mg} / \mathrm{l}$. Untuk air baku air minum, sumber air kadmium diperbolehkan mengandung kadmium maksimum 0,005 mg//13). 
Tabel-2 mengungkapkan bahwa selama penelitian, air W.S. Nongsa mengandung kadmium (Cd) antara 0,001-0,019 mg Cd/l; sementara itu PPRI No.82 Tahun 2001 menetapkan air air baku air minum hanya diperbolehkan mengandung kadmium sebesar 0,01 mg/l. Ini berarti bahwa meskipun Tabel-2 menunjukkan nilai $\mathrm{Cd}>0,01 \mathrm{mg} / \mathrm{l}$ hanya diperoleh 1 kali dari 7 kali analisis namun tetap harus disimpulkan bahwa berdasarkan kandungan cadmium; air W.S. Nongsa tidak memenuhi ketentuan air baku air minum.

\section{3) Kimia Organik}

Pada penelitian ini organik yang dianalisis hanya detergen. Detergen dalam badan air berasal dari limbah buangan rumah tangga dan industri. Limbah detergen perlu diperhatikan karena mengandung bahan aktif "surfaktan" yang dapat menimbulkan pengaruh negatif pada perairan. Keberadaan surfaktan dengn konsentrasi $1 \mathrm{mg} / \mathrm{l}$ dapat menimbulkan busa di perairan. Surfaktan meskipun tidak bersifat racun, namun dapat menimbulkan rasa dan menurunkan absorbsi oksigen di perairan ${ }^{8}$.

Salah satu pembangun (builder) detergen adalah polifosfat. Dengan demikian, deterjen dalam air akan melepas fosfat sehingga konsetrasinya meningkat. Sampai dengan konsentrasi tertentu, keberadaan fosfat dalam air memang baik karena meningkatkan produktifitas perairan, namun demikian seperti disebutkan sebelumnya, jika konsentrasi meningkat terus akan menimbulkan dampak negatif karena mengakibatkan yutrofikasi. Literatur yang ada menduga bahwa kontribusi limbah deterjen pada keberadaan fosfat dalam badan air telah mencapai $50 \%$.

Keberadaan deterjen dalam air dengan peruntukan air baku air minum ditetapkan oleh PPRI No.82 tahun 2001 tidak lebih besar dari 0,2 ppm MBAS. Sementara itu Tabel-2 menunjukkan bahwa air W.S. Nongsa mengandung deterjen antara 0,034-0,61 MBAS. Ini menunjukkan bahwa berdasarkan kandungan deterjen, air W.S. Baloi tidak dapat dimanfaatkan langsung untuk air minum. Tingginya kandungan deterjen ini diduga karena masyarakat sekitar W.S. Nongsa memanfaatkan tepian waduk sebagai tempat mencuci dan mandi

\subsection{Status Mutu Air W.S. Nongsa}

Penentuan status mutu air berdasarkan metoda STORET yang dicontohkan pada Keputusan Menteri Negara Lingkungan Hidup Nomor 15 Tahun 2003 tentang Pedoman Penentuan Status Mutu Air menghasilkan skor -67 untuk peruntukan Kelas-1. Kepmen 15 Tahun 2003, menyatakan bahwa air yang memiliki skor > 31; termasuk kelas $D$ yang tergolong air berkualitas buruk atau tercemar berat. Dengan demikian air W.S. Nongsa yang memiliki skor 67 juga tergolong air yang tercemar berat.

Mencermati Tabel-2 nampak bahwa pencemar utama W.S. Nongsa adalah COD, orthofosfat dan deterjen. Ketiga pencemar tersebut masing-masing menyumbang skor 16 sehingga hanya dengan jumlah skor ketiga parameter tersebut (-48); W.S. Nongsa sudah termasuk buruk (kelas D) untuk peruntukan air Kelas-1. Lebih jauh, Tabel-2 juga menunjukkan bahwa konsentrasi ketiga parameter tersebut sering lebih besar dari batas maksimum yang ditetapkan PPRI No. 82 tahun 2001. Fenomena ini mengisyaratkan bahwa W.S. Nongsa memang benar-benar telah tercemar oleh bahan organik.

Pencemar W.S. Nongsa yang lain adalah semua logam berat yang diukur, yang masih-masing memiliki nilai 4 . Mencermati Tabel-2 nampak bahwa sebenarnya dari 7 kali sampling (analisis) konsentrasi logam berat yang lebih besar dari ketetapan PPRI No. 82 tahun 2001 dicapai hanya 1 kali, yakni pada awal Februari 2007. Fenomena ini mengisyaratkan bahwa keempat logam berat tersebut dibuang masuk ke W.S. Nongsa tidak setiap saat, yang mungkin merupakan akumulasi limbah. Padahal jika limbah tersebut dibuang langsung (tidak diakulasi 
dahulu) mungkin tidak akan menjadikan konsentrasi logam-logam berat tersebut lebih besar dari ketetapan yang ada.

\section{KESIMPULAN DAN SARAN}

\subsection{Kesimpulan}

Mencermati pembahasan pada setiap parameter kualitas air tersebut diatas dapat disimpulkan bahwa berdasarkan Peraturan Pemerintah Republik Indonesia Nomor 82 Tahun 2001 tentang Pengelolaan kualitas air dan Pengendalian Pencemaran Air, air W.S. Nongsa memiliki beberapa parameter yang melebihi batas maksimum yang diijinkan sehingga tidak dapat langsung menjadi air baku air minum. Parameter tersebut adalah BOD, COD, Oksigen terlarut, total fosfat, kromium (Cr), timbal $(\mathrm{Pb})$, tembaga $(\mathrm{Cu})$, and kadmium $(\mathrm{Cd})$, dan deterjen. Akhirnya disimpulkan bahwa berdasar kan metode storet dalam Kepmen No. 115 Th. 20036) maka untuk peruntukan air baku air minum, air W.S. Nongsa termasuk Kelas D. Artinya air W.S. Nongsa sudah tercemar sehingga buruk bagi peruntukan air baku air minum.

\subsection{SARAN}

Mengingat W.S.Nongsa di bangun terutama untuk sumber air baku air minum. Maka ketidak layakan tersebut diatas perlu diatasi, dan untuk itu maka diperlukan: Pengkajian sumber penyebab tingginya konsentrasi parameter-parameter yang tidak memenuhi ketetapan PPRI N0 82 No. 2001. Kemudian dicari cara-cara penyelesaiannya, baik dengan pemanfaatan teknologi maupun kelembagaan. perhatian khusus pada kandungan logam-logam berat agar konsumen tidak mengakumulasi logam-logan tersebut, yang dikemudian hari dapat mendatangkan penyakit

\section{DAFTAR PUSTAKA}

1. Lemtek UI, 1991, "Final Report Evaluasi
Master Plan P. Batam", 1991.

2. Anonim, 1991. Penelitian kualitas air \& geohidrologi P. Batam. BPPT Jakarta

3. BIDA., 1992. Kebijaksanaan dan Strategi Pembangunan Pulau Batam, Paper Seminar Kesehatan Lingkungan Indonesia III.

4. APHA. 1985. Standart method for the examination of water and waste water. $16^{\text {th }}$ edition Washinton D.C

5. Anonymus, 2001. Peraturan Pemerintah Republik Indonesia Nomor 82 Tahun 2001 tentang Pengelolaan kualitas air dan Pengendalian Pencemaran Air

6. Keputusan Menteri Negara Lingkungan Hidup Nomor 115 Tahun 2003 tentang Pedoman Penentuan Status Mutu Air..

7. Garno, Y.S. 2003. Dinamika Kualitas dan Kelayakan Air Wduk Sei Harapan Menjadi Air Baku Air Minum. J. Tek. Ling. 4(1): 30-35.

8. Effendi, H. 2003. Telaah Kualitas Air Kanisius, Yogyakarta. 258 hal.

9. Rao, C.S. 1992. Environmental Pollution Control Enginering.Wiley Eastern Limited, New Delhi. 431 hal..

10. Jeffries, M. and D. Mills, D. 1996. Freshwater Ecology, Frinciples and Applications, John Wiley and Sons, Chichester, UK. 285 p. (10)

11. Cole, G. A. 1988 Textbook of Limnology. Third edition. Waveland Press, Inc., Illionis, USA.401 p. (11)

12. Henderson, B., Sellers dan H.R., Markland, 1987: Decaying Lakes "The Origins and Control of Cultural Eutrophication" John Wiley \& Sons, Chichester- Singapore, pp.

13. Moore, J.W. 1991. Inorganic Contaminants of Surface Water. Springer-Verlag, New-York.334 p.

14. EPA, "Water Quality Criteria," Ecological Res. Series, Washinton, 1972, 595 pp

15. Davis, M.L and D.A. Cornwell.1991. Introduction to environmental Engineering. Second edition. Mc-GrawHill,Inc., New-York. 822 p. 